To cite this article: Christine Greenhow \& Cathy Lewin (2016) Social media and education: reconceptualizing the boundaries of formal and informal learning, Learning, Media and Technology, 41:1, 6-30, DOI: 10.1080/17439884.2015.1064954

\title{
Social media and education: Reconceptualizing the boundaries of formal and informal learning
}

Christine Greenhow, Counseling, Educational Psychology and Special Education, College of Education, Michigan State University, East Lansing, MI 48824, USA

Cathy Lewin, Education and Social Research Institute, Manchester Metropolitan University, Cheshire Campus, Crewe, CW1 5DU, UK

It is argued that social media has the potential to bridge formal and informal learning through participatory digital cultures. Exemplars of sophisticated use by young people support this claim, although the majority of young people adopt the role of consumers rather than full participants. Scholars have suggested the potential of social media for integrating formal and informal learning, yet this work is commonly under-theorised. We propose a model theorising social media as a space for learning with varying attributes of formality and informality. Through two contrasting case studies we apply our model together with social constructivism and connectivism as theoretical lenses through which to tease out the complexities of learning in various settings. We conclude that our model could reveal new understandings of social media in education, and outline future research directions.

Keywords: Social media, informal learning, formal learning, digital cultures, teaching

\section{Introduction}

Technological advancements and pedagogies that emphasize learners as co-producers of knowledge (Selwyn 2011) have contributed to people's adoption of the term social media to indicate websites and online applications that enable users to create and participate in various communities through functions such as communicating, sharing, collaborating, publishing, managing, and interacting (Mao 2014; Social media, n.d. ). Typical social media features promote individual users through profile pages (eg., displaying likes, comments, recommendations). Social media features include interconnections with other users through links and news feeds, and sharing of user-generated content (eg., photos, ratings, tags). Pages can be dynamically updated and content embedded (eg., embedding a video). Examples of social media include social network sites (eg., Facebook); wikis (eg., wikispaces); mediasharing services (eg., YouTube); blogging tools (eg., Blogger); micro-blogging services (eg., Twitter); social bookmarking (eg., Delicious); bibliographic management tools (eg., Zotero); and presentation-sharing tools (eg., Slideshare) (Gruzd, Staves and Wilk 2012).

It has been argued that educators would benefit from 'a stronger focus on students' everyday use of and learning with Web 2.0 technologies in and outside of classrooms' (Greenhow, Robelia and Hughes 2009, 255). Others argue that only a small proportion of young people are actually using social media in sophisticated ways that educators might value (Eynon and Malmberg 2011; Ito et al. 2008). Complicating this tension, there is a lack of current models that theorise social media as a space for informal learning. There is also 
considerable debate about the benefits and challenges of appropriating technologies (e.g., social media) in everyday use for learning and little exploration of the connections between formal, non-formal, and informal learning such technologies might facilitate.

In this paper, we draw on relevant theory, prior literature and our own research in Europe and the United States to suggest a model that theorizes social media as a space for learning with varying attributes of formality and informality. Using ideas derived from social constructivism and connectivism as promising initial lenses through which to conceptualize social media and learning, this paper problematises 'learning' and 'teaching' across multiple contexts, illustrating the complex relationships between formal, non-formal, and informal learning. It considers research projects from two regions focusing on young people's uses of social media tools to support these varied forms of learning. Because our studies involve participants of varying ages including teenagers and college-age youth we refer to 'education' broadly as spanning school and higher education contexts. We revisit the debate about social media, or 'social software' in education to suggest how this model illuminates current tensions and suggests new opportunities for research and innovation.

\section{Research on social media in education}

The educational benefits of appropriating social media into learning contexts are contested. Research on social media in education suggests that integrating social media in learning and teaching environments may yield new forms of inquiry, communication, collaboration, identity work, or have positive cognitive, social, and emotional impacts (Gao, Luo and Zhang 2012; Greenhow, Burton and Robelia 2011; Greenhow and Robelia 2009a, 2009b; Pimmer, Linxen and Grohbiel 2012; Ranieri, Manca and Fini 2012). For instance, research on learning and social network sites (eg., Facebook) in particular has suggested their affordances for interaction, collaboration, information and resource sharing (Mazman and Usluel 2010); encouraging participation and critical thinking (Mason and Rennie 2007; Ajjan and Hartshorne 2008); increased peer support and communication about course content and assessment (DiVall and Kirwin 2012); inter-cultural language learning (Mills 2011); and their positive effects on the expression of identities and digital literacies, particularly for marginalised groups (Manca and Ranieri 2013).

On the other hand, researchers have warned against exploiting social media for learning. Kirschner and Karpinski (2010) found that time spent on Facebook negatively affected college grades. Similarly, Junco and Cotton (2013) examined how students multitask with Facebook and found that using Facebook while doing schoolwork was negatively associated with their overall grade point average. Students' use of social media in extracurricular activities was found to be distractive to learning, especially among weaker students (Andersson et al. 2014). Finally, students were less willing to appropriate social media as a formal learning tool, preferring it for course-related communication (Prescott, Wilson and Beckett 2013) or using it largely for socializing and non-academic purposes (Selwyn 2009).

Despite a growing body of work concerned with social media and 'informal learning', 'there has been little serious attention to the form or nature of that learning' (Merchant 2012, p16) or the interrelationship with formal learning (Cox, 2013). Many studies consider appropriation of social media within 'formal' and/or 'informal' learning, but in most cases these terms are under-theorized or treated as binary conditions, which oversimplify the complexities of the actual learning contexts today's youth inhabit. Some researchers suggest that appropriating social media can facilitate 'seamless' integration across learning situations 
integrating formal and informal learning (Dabbagh and Kitsantas 2012). Others highlight the challenges of appropriation (Crook 2012). Adopting a more 'principled approach' to understanding these tensions and interrelationships is especially important in light of recent technological developments, policy initiatives, changing teacher and faculty demographics, and the realities of young people's access to social media. As described in more detail below, these converging trends suggest it may be more useful and realistic to theorize social media as a space for learning with varying attributes of formality and informality.

\section{Theorising social media as a space for learning}

Social constructivism and connectivism are promising initial lenses through which to conceptualize social media and learning with varying attributes of formality and informality. Social constructivism draws on the idea that learning is situated in the context of circumstances, activity or culture. What is known resides not only in the individual, a position advanced by cognitive constructivists, but also in the collaboration and interaction among many (Vygotsky 1978; Windshitl 2002). Conceptually, social media practices seem well aligned with social constructivist views of learning as participation in a social context and values of knowledge as decentralized, accessible, and co-constructed among a broad base of users (Dede 2008); 'knowledge' may become 'collective agreement' that 'combines facts with other dimensions of human experience' (ie., opinions, values) (Dede 2008, 80). Validity of knowledge in social media environments can be negotiated through peer review in an engaged community, and expertise involves understanding disputes and offering syntheses accepted by the community (Dede 2008).

Similarly, connectivist ideas (Siemens 2005), which view learning as the process of creating connections and articulating a network with nodes and relationships, also seems well aligned with social media practices. Connectivism can best be viewed as a developing perspective (Kop and Hill 2008) that overlaps with other more established theory like social constructivism; it is under-researched but provides 'fertile testing ground for ideas, which, in turn, may lead to empirical research' that can then refine, validate or disprove the framework over time (Kop and Hill 2008, n.p.). Connectivism draws strength in using Internet activity as a powerful and intuitive analogy for conceiving of distributed learning through networks; if learning transpires via connections to nodes on the network, then perhaps the maximization of learning can be understood by studying the properties of effective networks (Kop and Hill 2008). From the connectivist perspective, being knowledgeable can be seen as the ability to nurture, maintain, and traverse network connections; to access and use specialized information sources just-in-time; and as the 'capacity to know more' rather than the individual's ability to construct meaning from prior knowledge, or 'what is currently known' (Siemens 2005, 4). Connectivism allows for non-linearity, unintentioned 'chaos' and unanticipated network effects in the learning process as learning occurs within 'nebulous environments of shifting core elements - not entirely under the control of the individual' $(2005,4)$.

Underlying these ideas are assumptions that boundaries between learning in and out of 'formal' education can be porous, slippery and perplexing (Barron 2004, 2006). Definitions of formal and informal (and non-formal) learning are contested and the interrelationships are complex (Colley, Hodkinson, and Malcolm 2003; Sefton-Green 2004; Selwyn 2007). Some models attempt to draw clear boundaries between each term (EC 2001; Livingstone 2001; Eshach 2007) whilst others suggest that informal and formal learning are on a continuum 
(Lai, Khaddage, and Knezek 2013; Sefton-Green 2004). Sefton-Green (2004, 6), for instance, suggests that distinctions can be 'more clearly made around the intentions and structure of the learning experience.' From a different perspective, Colley and colleagues suggest that it is impossible and unhelpful to separate informal, non-formal and formal learning (2003) at all. Rather they argue that 'It is more sensible to see attributes of formality and informality as present in all learning situations' (2003: Executive Summary, emphasis as in original). Furthermore, they suggest that the balance between these attributes varies and can influence the impact of learning. They describe an approach to considering the attribute balances which focuses on purpose (intentional/unintentional), process (structure, pedagogy, support, assessment, etc.), location (including norms and structures such as timetables in educational institutions), and content (high stakes knowledge to leisure interests). Although this work stems from the lifelong learning field, the authors relate the approach to school contexts, with one of four cases exemplifying their ideas in different contexts concerning a formal education institution for 16-18-year-olds (Colley, Hodkinson, and Malcolm 2003).

In recent debates, many authors have not attempted to problematize the terms formal and informal in relation to learning with social media. Informal learning is described as that which is not directed by school or externally mandated but is learner controlled (eg., Ferguson et al. 2014; Luckin et al. 2009; Tan 2013;), exploratory, self-directed and spontaneous (Dabbagh and Kitsantas 2012; Mardis 2013; Yang, Crook, and O'Malley 2013). Many use the terms to indicate context with formal representing the confines of the classroom and informal covering everything else from after-school clubs to the home (Ranieri and Bruni 2013; Reynolds and Chiu 2013). In some cases boundaries are acknowledged as not being clear-cut (Schuck and Aubusson 2010) and in others informal learning is conceived as closely entwined with formal learning (Ebner et al. 2010; Mardis 2013). Some authors avoid any explicit definition without any clear rationale for doing so (Chen and Bryer 2012).

Notions of informal learning are often compared with non-formal, not-school learning where one has certain objectives in mind (self-directed learning) and actively seeks information from sources that may include peers, mentors, or media (Sefton-Green 2004; 2013). Both terms typically contrast with definitions of formal learning situations in which some agent - a teacher, an educational software program, or a learning management system - is directing the student's learning. The agent guides the student through a formalized set of objectives typically generated by an outside authority, such as curriculum standards developed by professional organizations or mandated by the government.

In reality we draw on social constructivist and connectivist ideas and the work of Colley, Hodkinson, and Malcolm (2003) to argue that students may practise learning with formal, informal, and non-formal attributes across a wide range of contexts and exercise considerable authority over how they learn, when they learn and with whom. In Table 1 we outline our model for theorizing social media as a space for learning with varying attributes of formality and informality.

Table 1. A model of learning attributes, adapted from the work of Colley, Hodkinson, and Malcolm 2003

\begin{tabular}{|l|l|l|l|}
\hline Category & Formal attributes & Informal attributes & Social media attributes \\
\hline Purpose & Learning as primary & Learning as unintended & Communication \\
& purpose (intentional) & outcome (or not recognised) & Creating \\
& & Casual learning & Sharing \\
\hline
\end{tabular}




\begin{tabular}{|c|c|c|c|}
\hline & & & $\begin{array}{l}\text { Connecting } \\
\text { Playing } \\
\text { Consuming }\end{array}$ \\
\hline & $\begin{array}{l}\text { Externally determined } \\
\text { (eg. curriculum standard) }\end{array}$ & $\begin{array}{l}\text { Self-determined } \\
\text { Community of interest }\end{array}$ & $\begin{array}{l}\text { Self-determined } \\
\text { Socially-determined }\end{array}$ \\
\hline & $\begin{array}{l}\text { Audience for student } \\
\text { work is closed, known } \\
\text { (teachers, parents, } \\
\text { classmates) }\end{array}$ & $\begin{array}{l}\text { Audience for student work } \\
\text { may be closed/known or } \\
\text { open/unknown or variation }\end{array}$ & $\begin{array}{l}\text { Audience for user- } \\
\text { generated content may be } \\
\text { closed/known or } \\
\text { open/unknown or } \\
\text { variation }\end{array}$ \\
\hline \multirow[t]{6}{*}{$\begin{array}{l}\text { Process of } \\
\text { Learning }\end{array}$} & Teacher-initiated & $\begin{array}{l}\text { Incidental, experiential, } \\
\text { spontaneous }\end{array}$ & $\begin{array}{l}\text { Self-initiated } \\
\text { Peer- or other-influenced }\end{array}$ \\
\hline & Teacher-led (didactic) & $\begin{array}{l}\text { Self-directed (negotiated) } \\
\text { Individual agency }\end{array}$ & $\begin{array}{l}\text { Self-directed } \\
\text { Peer- or other-influenced } \\
\text { Unintended network } \\
\text { effects }\end{array}$ \\
\hline & Teacher support & Peer/friend support & Network support \\
\hline & $\begin{array}{l}\text { Summative assessment } \\
\text { Formative assessment } \\
\text { Individual Accountability }\end{array}$ & Feedback & $\begin{array}{l}\text { Community evaluation } \\
\text { (rating, commentary, } \\
\text { bookmarking) }\end{array}$ \\
\hline & $\begin{array}{l}\text { Teachers as Authority } \\
\text { Students can provide } \\
\text { input }\end{array}$ & Democratization of expertise & $\begin{array}{l}\text { Expertise via } \\
\text { participation }\end{array}$ \\
\hline & $\begin{array}{l}\text { Predominantly text- } \\
\text { based, some multimedia }\end{array}$ & Varies & $\begin{array}{l}\text { Multimodal (eg. Images, } \\
\text { videos, tags, ratings, } \\
\text { hyperlinks) }\end{array}$ \\
\hline \multirow[t]{5}{*}{$\begin{array}{l}\text { Location/ } \\
\text { context }\end{array}$} & $\begin{array}{l}\text { Educational institution } \\
\text { (e.g., school) }\end{array}$ & $\begin{array}{l}\text { Home, community, museum, } \\
\text { after-school club (eg. out of } \\
\text { school) }\end{array}$ & $\begin{array}{l}\text { Online, ubiquitous } \\
\text { (subject to internet } \\
\text { access) }\end{array}$ \\
\hline & Time-restricted & Open-ended & Open-ended \\
\hline & Learning objective & No learning objective & Varies \\
\hline & Certification & No certification & $\begin{array}{l}\text { Individual recognition } \\
\text { (e.g., badge) } \\
\text { Social recognition }\end{array}$ \\
\hline & Curriculum & No curriculum & Varies \\
\hline \multirow[t]{3}{*}{ Content } & Knowledge acquisition & Everyday practice & $\begin{array}{l}\text { User-generated, } \\
\text { Re-mixed }\end{array}$ \\
\hline & High status knowledge & $\begin{array}{l}\text { Status of knowledge } \\
\text { irrelevant/unacknowledged }\end{array}$ & $\begin{array}{l}\text { Social construction and } \\
\text { distribution } \\
\text { Knowledge as collective } \\
\text { agreement }\end{array}$ \\
\hline & Specified outcomes rigid & $\begin{array}{l}\text { Specified outcomes flexible } \\
\text { or serendipitous }\end{array}$ & $\begin{array}{l}\text { Outcomes vary } \\
\text { Unintended network } \\
\text { effects }\end{array}$ \\
\hline
\end{tabular}

Our model summarises the attributes proposed by Colley, Hodkinson, and Malcolm (2003), recognising the issues arising in reducing complex concepts to a series of labels. For example, such attributes can be contested, interpreted differently and may not be of equal importance in different learning contexts (Colley, Hodkinson, and Malcolm 2003). Moreover, 
'[S]ome of the "polar opposites" might actually co-exist' (Colley, Hodkinson, and Malcolm $2003,9)$. We have developed the attributes further by considering what learning attributes may be specific to social media contexts. Our model is intended to offer a starting point for discussion rather than be a pre-defined solution to the issue of understanding the complexity of learning. In our work it has enabled us to tease out and problematize the impact that social media has in educational contexts.

\section{Blurring boundaries: Digital cultures outside and digital practices within educational institutions}

We argue it is becoming increasingly important to conceive of learning with varying attributes of formality and informality as pedagogical practices drawing on aspects of formal and informal learning become more commonplace (Weigel, James, and Gardner 2009). Second, it is argued that '[d]idactic methods like self-directed learning, explorative or research-based learning offer particular potential for informal learning because of the low influence of teachers and the fact that learning is not primarily aligned to teaching' (Ebner et al. 2010, 93). Similarly, it has been suggested that learners are increasingly bringing informal practices (including digital tools such as social media) into formal educational contexts (Trinder et al. 2008). To illustrate these blurring boundaries we consider two converging trends: 1) the growth of digital cultures outside educational institutions, and 2) the lack of digital practices in educational institutions.

With the growth of social media use (Brenner and Smith 2013; Madden et al. 2012; Ofcom 2014), people (young and old) can engage in participatory digital cultures (Jenkins et al. 2009), potentially benefitting from collaborative learning, the development of new skills and greater agency. Research suggests that young people are engaging in a variety of digital practices with social media. For example, Ito and colleagues (Ito et al. 2013, 6) present case studies of 'connected learning,' defined as 'learning that is socially-embedded, interestdriven, and oriented toward educational, economic or political opportunity.' These case studies include young people engaged in an online fiction-writing community, creating and developing an online comic, and engaging in an online civil action community. Of course, not all young people participate to the same degree. Participation can be characterized as hanging out (maintaining social connections), messing around (playing with technology) and geeking out (intense, autonomous engagement) (Ito et al. 2008). However, participatory digital cultures illustrate how the lines between self-directed, intentional learning and spontaneous, incidental and experiential learning are blurring, certainly in 'informal' contexts

On the other hand, there is still significantly less use of digital technologies in 'formal contexts' and the kinds of use do not always take account of the richness of some (but not all) learners' experiences outside institutions (Clark et al. 2009; Warschauer and Matuchniak 2010). Appropriation of technologies by educators is often used to replicate traditional approaches and is thus at odds with the creative practices in participatory digital cultures (Green and Hannon 2007; Warschauer and Matuchniak 2010). Clark et al. (2009) suggest that the intersection between digital cultures and institutional Information and Communication Technologies practices is a space dominated by 'digital dissonance' with both educators and learners unable to recognise the potential benefits of social media for formal education. As several researchers have pointed out, stemming this disconnect between institutional digital practices and what some learners experience out of school may become especially important to addressing educational inequities; for example, for children in rural or low-income areas, 
inside school spaces may be their only opportunities to access technology-rich informal learning opportunities (Mardis 2013; Eynon 2009).

These examples suggest that technology has the potential to disrupt the boundaries between sites where learning takes place. It can empower learners through greater agency, opportunities to participate in networked communities and access to a wide range of resources to support knowledge building and collaboration. There seems little doubt that engagement with digital cultures offers potential for self-directed or spontaneous learning opportunities of varying degrees. Within educational policy circles and the research community, there has been much interest recently in adopting informal learning practices in formal institutions.

Next, to illustrate the theoretical model (Table 1), we present two research projects focusing on young people's uses of social media for learning with varying attributes of formality and informality. We revisit the debate about social media, or 'social software' in education to suggest how our proposed model illuminates current tensions and suggests new opportunities for research and innovation.

\section{Interrogating social media as space for learning: applying our theoretical model to empirical data}

In the first study (Lewin and McNicol 2014), which focused on mechanisms to transform and scale-up the use of technology in compulsory education, teachers in primary and secondary schools from 20 different countries were provided with resources and processes to stimulate technology-enabled pedagogical innovation. The resources developed were underpinned by a commitment to promote 'twenty-first-century skills'. Whilst acknowledged as a contested concept - some argue that twenty-first-century skills cannot be taught in isolation and that core content needs to be the primary educational focus (Mathews 2009; Silva 2009) competences commonly referred to in various twenty-first-century skills frameworks and definitions (eg. Binkley et al. 2012; ISTE 2007; P21 2009) include collaboration, communication, ICT, creativity, critical thinking and problem-solving (Voogt \& Pareja Roblin 2012) Thus, for example, social media tools, such as Facebook, blogs and wikis, were recommended to teachers to support learning activities such as collaboration and communication. The evaluation took place over five cycles of activity (2011-2014) and involved teacher surveys and case studies of resulting projects. Teachers were asked about their uses of social media, including the benefits and challenges they experienced. As part of the case studies, group interviews with students were undertaken and they were asked how the use of technology in school differed from their uses of technology at home.

The second study (Greenhow 2011; Robelia, Greenhow, and Burton 2011), conducted with young people, aged 16-25, in the USA, explored the nature of young people's use of a Facebook application called Hot Dish in their everyday lives. The application was designed in 2009 to accommodate young people's knowledge-sharing about environmental science issues and provide opportunities to participate in civic actions related to global warming and climate change. Of the 1,100 registered members, 322 users opted into the study and voluntarily used the application. Participants were observed regularly over two months. Data were collected in the form of online surveys; online focus groups $(n=16)$ and semi-structured interviews $(n=12)$ with a purposeful sample of high/medium/low users; online comment strings in response to articles (related to environmental science); and from online statistics: 
automated data tracking provided ongoing statistics of Hot Dish usage, per user and per feature. This paper revisits the survey, comment string, and site usage statistics data.

Next, we present each project in more detail and then draw on our model for theorizing social media as a space for learning with varying attributes of formality and informality in order to characterize and highlight the themes evident from each project. We also summarize the benefits and challenges of appropriating social media as evidenced in each study.

\section{The European study: Embedding social media in formal education}

The Innovative Technologies for an Engaging Classroom (iTEC) project took place from September 2010 to August 2014. It focused on education in school contexts, primarily targeting learners aged between 7 and 14. In the first 4 of 5 cycles, teachers from 20 European countries were provided with resources to support pedagogical innovation with technology. For each cycle, a package of learning activities (concrete descriptions of learning sequences for teaching and learning) was developed through desk-based research and participatory design processes with teachers. The package of learning activities was exemplified through learning stories, narrative overviews of learning developed from more abstract educational scenarios. The resources describing the learning activities included recommendations for embedding technologies to support the pedagogical approaches. In all four cycles, social media (Facebook, Twitter, blogs, wikis, etc.) were suggested in three out of five learning activities and thus were central to the pedagogical changes recommended to teachers. This is not surprising, given that the development of twenty-first-century skills underpinned the aims of the classroom redesign process (Lewin and McNicol 2014), with an emphasis on collaboration, communication and creativity, as well as digital literacy; social media, with its affordances mentioned earlier, seems well positioned to support such skills in the classroom. Therefore, through the project, teachers were encouraged to adopt social learning approaches supported by a range of social media tools. For example:

- The Peer Feedback learning activity (cycle 1) incorporated blogs and wikis.

- The Learning Oriented Browsing learning activity (cycle 2), involved searching the internet to gather links on a topic and incorporated social bookmarking tools.

- The Reflection learning activity (cycles 2-4), required students to reflect on progress at regular points during the project and incorporated collaborative tools such as Voicethread as well as tools (apps) developed as part of the project.

- The Show learning activity (cycle 4) involved publishing and presenting designs to an audience, incorporating the use of video-sharing sites such as YouTube.

The resources were not presented as lesson plans or scripts, but as sources of inspiration for teachers. As a result, teachers developed projects that were tailored to their individual needs and their school context. Teachers and students used a wide range of digital tools from media recording to games-making and $3 \mathrm{D}$ design/printing. In cycle 2, social networking sites were specifically promoted, resulting in half of the participating teachers $(n=261)$ and their students embedding their use in the projects they undertook. In some cases, teachers opted for education-specific tools such as Edmodo (described as 'a social learning network') due to security concerns and the school's site blocking practices with regard to sites such as Facebook. As an education-specific tool used at the direction of the teacher, many formal learning attributes were present. 
For instance, social media were used by students for a number of purposes (primarily for teacher-initiated, intentional learning):

- Managing group work (finding partners, forming groups, sharing tasks)

- Generating ideas

- Communication with peers and teachers (group discussion, asking questions, receiving feedback)

- Sharing information, resources and links

- Documenting and communicating progress (sometimes to audiences beyond the classroom)

- Sharing project outcomes such as presentations

- Assessment and evaluation (peer, teacher)

In cycle 3 , blogs were specifically promoted with $56 \%$ of teachers $(n=334)$ reporting that students had used them to support their projects. Technology-enabled reflection through blogs developed students' metacognition and self-evaluation, supported peer learning, and enabled students to refine their ideas. The most significant benefit perceived by teachers was that blogging facilitated the sharing of ideas and resources between students. Teachers perceived that this technology changed how teachers and students interacted with each other, increasing teacher-student communication and enabling peer tutoring and peer feedback. Teachers also noted that they were able to monitor students' progress more easily. There were, of course, challenges for teachers including the time investment required, changing student attitudes, developing students' digital literacy skills and infrastructure/resource constraints.

An unexpected outcome of the blogs is that students from other classes and schools left comments and suggestions for the class' students. All of the posts were encouraging and constructive and students appreciated this feedback. (Case study report, France, Cycle 2)

In Italy, in cycle 4, a teacher of Science at a secondary school decided to run a project over six weeks. The topic was volcanoes and teams of students were asked to design and produce prototype learning objects in game formats to convey knowledge to other students. The students decided what to focus on and how to present the learning (some aspects of the process were student-led). Initial proposals were discussed and refined within and between groups through the use of blogs and a closed Facebook site. In this school, access to Facebook was normally prohibited. The groups produced prototypes such as: a crossword puzzle (on volcanoes) produced with the software 'Hot Potatoes', a quiz for interactive whiteboard responders, a physical interactive model (made with traditional materials), and a videogame (made with Unity 3D software). Through a participatory design workshop approach, the teams presented their prototypes to other learners, the head teacher and a geology expert. This was organised in the style of 'Italia's got talent' with a 'jury' trying out the prototypes and providing feedback to the teams. The teacher noted that a risk of using Facebook in the classroom was that students would use it for non-school related activities. However, she commented that the way to address this challenge was to 'give clear tasks, clear deadlines' (arguably, relying on formal rather than social media attributes).

\section{Revisiting the data through a new lens}

We now consider this study of embedding social media in the classroom in the light of varying attributes of formality introduced in Table 1. In relation to purpose, the projects were 
to facilitate intentional learning and determined externally (by the teacher). However, with greater autonomy, students helped to shape the learning activities; thus aspects were selfdetermined and also socially determined as they predominantly worked in groups. In relation to process, to varying degrees, teachers gave greater autonomy and control to their students. The projects were self- and peer-directed and negotiated by students, who were given choices and flexibility. Moreover, unintended network effects shaped both the process and content of learning in ways not determined by the teacher, as in the case of the blogging activity where positioning students' work in a semi-public space resulted unexpectedly in other students, outside the class, leaving comments on students' work. Through the greater use of technology students represented their learning in a more multimodal way. Arguably the teachers in many cases relinquished much of their authority, adopting a more supportive and guiding role. However, the process remained teacher-initiated.

Considering the location and context, activity was open-ended although still within a loose structure and guided by the package of learning activities selected by a teacher. With a greater use of technology, more of the activity took place online both in school and outside school with work continuing on students' own time. Given the purpose of schooling, the activities were driven by formal attributes with learning objectives and a need to meet the demands of the curriculum. In relation to content, again given the context there was, of course, an underpinning aim of knowledge acquisition. However, there were perhaps subtle shifts towards user-generated knowledge (through enquiry processes) and social construction and distribution of knowledge. The use of social media, like Facebook, provided students with opportunities to engage in network support, and for their Friends' network to interact with and contribute content in ways both unplanned and unseen by the teacher. The status of knowledge in educational settings may always be acknowledged and validated but what counts as knowledge may be more contestable perhaps when social media is incorporated. This example highlights the complexities of teasing out formal and informal attributes of learning and the limitations of reducing formal and informal learning to binary opposites. Examples from this project would be categorised as formal learning (all teacher initiated) when clearly the use of social media combined with pedagogical shifts introduces a wider variety of learning attributes; the boundaries between formal, informal and social media learning are becoming increasingly blurred such that some attributes are difficult to discern and categorise.

Moreover, in this case, the benefits of appropriating social media were substantial. It supported the development of twenty-first-century skills including collaboration, creativity, and communication. Social media effectively enabled students to become more autonomous and develop metacognition. Furthermore, if facilitated new approaches to supporting assessment and reflection. Students were able to share their learning and knowledge construction with each other and with teachers and students from other schools (in some cases in other countries). However, the challenges remain similar to those identified in the first example. School policies blocking access to social media and concerns about privacy issues are inhibiting appropriation of these tools to support teacher-initiated learning. This drives some to adopt social media developed specifically for compulsory education; and with this comes a greater emphasis on formal learning attributes as teachers feel the need to exert greater control and put more rigid structures in place. 


\section{The USA study: Examining the digital culture of an environmental science-oriented Facebook application}

This study - exploring young people's voluntary use of a Facebook (FB) application (i.e., Hot Dish) for knowledge sharing about environmental science issues and engagement in related civic actions - provides another window into a youth-initiated digital culture.

The Hot Dish project took place from September 2008 to May 2009. It focused on learning online outside of school, primarily targeting learners aged between 16 and 25 . The analysis presents examples of formal and informal learning attributes at play in students' everyday life.

\section{Design of the Hot Dish Facebook application}

As a free FB application that young people voluntarily allowed to interact with their FB account, Hot Dish was both 'expert'-driven and user-generated; an environmental partner (which published a print-based magazine) continually updated Hot Dish with information related to the topic of interest (conceptual pieces, scientific reports, policy articles, howto/lifestyle guides related to environmental science and climate change issues). However, also Hot Dish offered multiple channels for users' contributions about environmental issues. Membership was initiated by inviting the magazine's subscribers to join and subsequently driven by existing members inviting friends.

Features of Hot Dish included the ability to post original story entries (in text, video and images), or circulate articles from online sources. Members could read an article's summary or read the full article; curate and rank posted articles: voting them up, commenting on them and sharing them within or outside the social network. Individuals created a self-profile in Hot Dish similar to their Facebook profile (the parent site); members portrayed their background, interests, and ideas through online photos, bio, and a data-reporting feature which showcased the artefacts and activities they contributed within Hot Dish. The Action Team area of the app facilitated members' participation in civic action challenges designed to address environmental issues within their communities through online or offline activities (for example, signing online petitions or lobbying local businesses). Completion of challenges was tracked through a points system with a range of prizes for high scorers from ringtones to organic t-shirts to a trip for two to the arctic; the system highlighted challenge leaders. Challenge completion required uploading documentation (text, video, images) for subsequent evaluation by the site moderator (a member of the research team) (Greenhow 2010).

Site usage statistics revealed that Hot Dish was successful in attracting a base of users who actively participated in reading, posting and commenting on articles. Valid survey responses from the 322 users who opted into the study were collected from 111 Hot Dish members for a response rate of $32 \%$. Sixteen users participated in two online focus groups of eight members. Drawing on these data revealed that participation in Hot Dish spurred many participants to express their opinions, engage in debate, learn more about climate change and do more to limit its impact.

\section{Participating in civic actions}

For instance, the online survey revealed that Hot Dish users reported an increase in their proenvironmental behaviours during their involvement with the Facebook application. Hot Dish offered 56 different challenges to help users become involved in enacting pro-environmental 
changes in the community; Hot Dish users completed 1523 of these problem-solving challenges, about $25 \%$ of which were from the category of challenges known as activism in the local community. Local activism challenges included attending a town meeting, writing a letter to the editor of a local paper, writing a local lawmaker, attending events to network with environmentally minded others, starting an environmental group or recycling program, volunteering for an environmental group, and taking part in Earth Day, a worldwide awareness-raising event.

Social aspects of Hot Dish motivated young people to participate and contribute more to this site than to other websites they frequented. The majority of survey respondents reported being more motivated to use Hot Dish to interact with like-minded people (72\%) and to express their opinions $(62 \%)$ than they reported for other websites. Focus group participants reported feeling "safer" making comments on Hot Dish rather than on other sites because it felt more receptive - for example, a community of 'kindred spirits', with shared concerns for the environment and interest in reducing global warming.

Survey responses regarding how users connected with others within Hot Dish indicated that the majority connected by: (1) reading articles posted by other members $(77 \%),(2)$ reading comments on posted entries (69\%), and (3) completing civic action challenges with others $(53 \%)$. In fact, young people reported in focus groups that seeing, in their news feed, how others were making a difference in their community, through the Hot Dish civic action challenges, catalysed their latent interest in also making a difference and then, the site's list of action challenges and incentives helped to turn that interest into action.

Moreover, focus group data revealed that users' Facebooking habit equalled their Hot Dish habit. Not surprisingly, survey results indicated that Hot Dish users were frequent users of Facebook (98\%). Moreover, many of the focus group participants said that locating the application within FB made it easy to check up on environmental issues on a regular basis because they were in the habit of checking FB anyway. Focus group participants in the high user group were especially likely to mention how participation in the Hot Dish community became part of their daily Facebooking routines, as JL commented, 'Now it [Hot Dish] is just part of my "Facebooking".' I probably look at Hot Dish $90 \%$ of the time I log into Facebook'. Another participant mirrored JL's sentiment, 'I just got into the habit of checking in whenever I was using Facebook'. NB commented that the FB application was helpful in making it easy to check, 'The design of the website within Facebook kept me interested and looking for more'.

\section{Participating in issue-oriented debate}

Across the study period, young people on Hot Dish read 2103 articles, $89 \%$ of the total possible; they contributed 2153 comments. Of these, 220 articles included three or more comment strings. To investigate whether and how young people actually engaged in substantive debate about the focal topic - a goal for users when designing the app - these comment strings were coded for evidence of argumentation about environmental issues (Greenhow, Menzer, and Gibbins 2015); extending an argumentation coding system originally designed for 'formal' computer-supported collaborative learning environments (Sadler, Barab, and Scott 2006; Weinberger and Fischer 2006), comments strings were coded for four argumentation dimensions: participation, epistemic, argument, and social coconstruction skills. Results indicated that these three skill subsets were also evident in the Hot Dish environment at relatively high rates. 


\section{Revisiting the data through a new lens}

Considering this study of the Hot Dish digital culture in light of the varying attributes of formality and informality introduced in Table 1, we see that this case demonstrates the use of social media for varied purposes; young people were intentional in seeking to interact with like-minded people and contribute, as well as consider, others' ideas about a shared interest: environmental issues. However, their learning was also unintentional and socially determined; seeing others in the Hot Dish network perform civic actions sparked people's intention and awareness of how they, too, could contribute, and in turn, they engaged. In addition, when young people posted comments or documentation of completed civic actions, they were both 'speaking' to their intended audience of other known Hot Dish users (all Hot Dishers can see each other's profiles) as well as to an unintended audience of subsequent users invited into the site.

In terms of process, learning was self-initiated and self-directed as young people chose which articles to debate and which actions to perform, if any. The process of learning was also peer influenced as the analysis of argumentation clearly showed how individual's comments, such as a consensus-building comment or counterargument shaped the dialogue that was constructed; however, the collaboration of educational technologists, software designers and magazine editors, perhaps loosely akin to 'teachers', also initiated and guided the learning process with features designed to encourage debate and incentivize particular kinds of performances over others (e.g., particular activities such as commenting, sharing, completing a civic action held higher point values than others such as liking a comment). Expertise in Hot Dish was both pre-authorized and negotiated. The educational technologists evaluated documented completions of civic actions and awarded points, and the magazine editors determined, in part, what articles the community read. On the other hand, expertise was negotiated through participation. For instance, certain users becoming known within the community through their superior point totals, which earned them ever-increasing titles (e.g., individual recognition such as the Climate Czar badge) and recognition from peers for the quality of their online contributions (e.g., social recognition through 'likes' on their comments or articles they contributed being 'voted up' as most popular or most read). In this project, we see that the location for learning was in some ways open-ended and not timedependent, but in other ways, fixed in time. For example, participants could engage from any location and time in which they checked into their Facebook account. On the other hand, the points competition was somewhat fixed in time, with prizes awarded at the end of the twomonth period. In relation to content, pursuing personal interests relates to everyday practice rather than high status knowledge. However, the design of this Facebook app was informed by a growing consensus within the science education community that fostering learners' debate about controversial socio-scientific issues (e.g., climate change) can facilitate their development of contemporary scientific literacies (Greenhow, Menzer, and Gibbins 2015; Robelia et al. 2011; Sadler et al. 2006). Thus, in Hot Dish, young people's interests and the designers intentions help link everyday practices with social media to high status knowledge and learning opportunities valued in education.

This example also demonstrates the benefits and challenges of appropriating social media for learning. Piggy-backing on young people's existing, regular Facebooking activities (their digital cultural practices), Hot Dish provided an outlet to move beyond social networking mainly for socializing to debating socio-scientific issues of common interest, collaboratively pursuing civic actions, and networking related to their school- or career interests. It not only facilitated easy access to expertise (the publishing company, the research team) but also supported knowledge creation through community interaction. The community of like- 
minded people offered a 'safe' environment to test out ideas and receive feedback on actions. The support structures in place, such as gamification (i.e., point awards, badging) stimulated young people's engagement in the community. Hot Dish supported learning and environmental activism without the restrictions associated with formal learning attributes. Challenges to appropriating this or similar social media relate to the structures required to ensure success including development, technical support, and assessment. For example, assessing whether or not, and how well, young people had documented their completed civic actions required the team to constantly monitor the site and provide feedback in a timely manner so that users would see their point awards. A greater emphasis on informal learning attributes comes at a cost; sustaining this and similar projects will be an ongoing challenge where both time and money are limited in education. Furthermore, given the approach to recruitment, relatively few young people were geeking out (Ito et al. 2010) in the community.

\section{Conclusions}

The two studies offer a different perspective on young people's social media use. The European study focuses entirely on the embedding of social media in school classrooms. The activities were primarily initiated and driven by classroom teachers rather than emerging from young people's interest-driven social media use for self-defined purposes. Therefore, it might be judged by others to be an example of 'formal' learning. In contrast, the USA study illustrates a community initiated and over seen by 'experts', but whose content, purpose, and actions were driven largely by contributions from the network members. Given that the community existed independently of formal educational institutions, it could be described as 'informal' learning. However, through the analytical lens of our theoretical model, we have teased out the complexities of these two examples of learning by considering the informal and formal learning attributes at play.

In both cases, social media offered opportunities for young people to harness the power of the network and seek relevant expertise. In the European study, social media use generated opportunities for unexpected network effects through interactions with peers outside the school walls, shaping young people's knowledge construction in unexpected ways. In the USA study, co-construction of knowledge was encouraged through publication of 'articles,' which sparked constructive debate about socio-scientific issues and subsequent community interaction. Moreover, both cases demonstrated some elements of self-determination (in terms of learning purpose) and self-direction (in terms of learning process). In the European study, this introduced more informal learning attributes than had been present in the formal educational context of the classroom previously. However, in this example, the initiation and direction of learning activities by the teacher constrained some of the freedoms associated with information-learning attributes. Indeed, as illustrated above, one teacher adopted more formal structures (clear tasks, tight deadlines) in order to counter some informal practices that were not perceived to hold a legitimate place in formal education.

There are clearly challenges which need to be overcome when educational institutions such as schools try to harness the potential benefits of digital cultural tools. Our data raise issues around control and surveillance. In UK schools, for example, moral panics about e-safety issues have continued and will continue to constrain access to popular social networking sites and publicly accessible tools such as blogs and wikis. As a result, in many cases, educationspecific social media tools are appropriated rather than those in common use. Such tools are necessarily and recognisably different, offering a different balance of formal and informal 
learning attributes, and often restricting the degree of control that learners have over aspects such as direction, audience and assessment. This can constrain the opportunities for harnessing the potential benefits of social media such as learning through connecting (e.g., Ito et al. 2013; Siemens 2005). Nevertheless, staff from schools in the European study reported here perceived that adapting tools from digital cultures for formal education can be beneficial. The integration of social media in institutional practices necessitates reconsidering support structures and legitimising practices that may have previously been dismissed. For instance, further exploration of the use of social recognition or community evaluation as valid forms of assessment in formal contexts would be beneficial. This could facilitate unintended network effects, shifting some of the burden for feedback and assessment from the teacher (or editor/other central authority) to other relevant and realistic/authentic audiences for the work, such as peers or topic-oriented community. The model presented in this paper could be used to help educators and senior managers understand the new possibilities for learning offered though social media.

Moreover, the model introduced in this paper helps to illuminate some of the aforementioned tensions between educational policy imperatives and reported outcomes, although contested, of young people's everyday social media practices. For instance, a decline in young people's print-based literacy (NEA 2007) and civic engagement (Putnam 1995) and increase in out-ofschool online reading, writing, and activities (NEA 2007) have prompted educators' questions about what it means to meaningfully participate in the digital age. The findings of the US study suggest that educators and educational researchers might do well to suspend a rush to judgement that young people's leisure-time, social media practices are necessarily a waste of time or downright harmful to their becoming informed, literate, and engaged citizens. On the contrary, they argue for greater understanding of how young people's participatory media practices in third spaces between formal schooling and home might be designed to facilitate the kinds of social-academic resources that support students towards becoming educated and fully contributing societal members. These include providing students opportunities to: meaningfully connect with peers; receive prompt feedback on content-related questions or performances; use peers as mentors; derive enjoyment from belonging to something larger than themselves; encounter diverse perspectives; and apply formal schooling (e.g., technological literacies, writing strategies) to tackling meaningful socio-scientific issues in their lives.

Social media has unique and powerful features, readily facilitating connections to others (Ito et al. 2013; Siemens 2005) through sharing and community evaluation, leading to participatory engagement in effective, multimodal learning communities. Further research and design work is essential to harness the potential benefits of social media for learning in both formal and informal contexts. We need more research-and-design projects, like the US study, in which learning technology designs are grounded in the competencies that educators value (e.g., socio-scientific argumentation, civic engagement, and modern scientific literacy) but open-ended and user-driven to enable participatory cultures to emerge. Such research should focus not only on the experiences of participants but also on the structural models underpinning such learning communities to investigate how to achieve sustainability. There is also a need for more research on adolescent learning with social media, since research to date has focused primarily on college students in higher education settings. Finally, we need more research that examines learning in digital cultures which is perhaps more ethnographic in nature and certainly foreground the learning, irrespective of purpose, process, location or content. For example, rather than studying Facebook activity in the classroom, research 
should focus on its use across all contexts in which it is used and focus on the learning opportunities that arise.

Some young people, although in the minority, are engaging fully, initiating self-directed learning activities utilising the full potential of participatory and collaborative technologies. Harnessing the learning attributes of social media could enrich young people's experiences of learning in institutional contexts. However, it is necessary to fully explore the complexities of the learning landscapes in order to understand how to challenge and disrupt institutional policies and practices, whilst being mindful of the need to avoid the reproduction of technology-based power structures (Greenhow and Gleason 2014; Selwyn 2010). We suggest that in relation to social media, consideration of varying attributes of formality (Colley, Hodkinson, and Malcolm 2003) is one means of achieving this. 


\section{Acknowledgement}

The iTEC project was supported by the European Commission under Grant Agreement No: 257566. The Hot Dish project was supported by a grant from the John S. and James L. Knight Foundation.

\section{Notes on contributors}

Dr Christine Greenhow is an Assistant Professor of Educational Psychology and Educational Technology in Counseling, Educational Psychology, and Special Education at the College of Education, Michigan State University.

Dr Cathy Lewin is a Professorial Research Fellow and Co-Director of the Centre for Research in Technology, Innovation and Play for Learning (TIPL) research group at Manchester Metropolitan University.

\section{References}

Ajjan, H., and R. Hartshorne. 2008. "Investigating faculty decisions to adopt Web 2.0 technologies:

Theory and empirical tests." The Internet and Higher Education 11 (2): 71-80.

Andersson, A., M. Hatakka, A. Grönlund, and M. Wiklund. 2014. "Reclaiming the students - coping with social media in 1:1 schools." Learning, Media and Technology 39 (1): 37-52.

Barron, B. 2004. "Learning Ecologies for Technological Fluency: Gender and Experience Differences." Journal of Educational Computing Research 3 (1): 1-36.

Barron, B. 2006. "Interest and self-sustained learning as catalysts of development: A learning ecologies perspective." Human Development 49: 193-224.

Binkley, M., Erstad, O., Herman, J., Raizen, S., Ripley, M., Miller-Ricci, M., \& Rumble, M. 2012. "Defining Twenty First Learning Skills." In Assessment and Teaching of 21st Century Skills, edited by P. Griffin, B. McGaw, and E. Care, 17-66. Dordrecht: Springer.

Brenner, J., and A. Smith. 2013. 72\% of Online Adults are Social Networking Site Users. Washington, DC: Pew Internet \& American Life Project.

Chen, B. and T. Bryer. 2012. "Investigating instructional strategies for using social media in formal and informal learning". The International Review of Research in Open and Distributed Learning, 13 (1): 87-104, Available at:

$<$ http://www.irrodl.org/index.php/irrodl/article/view/1027/2073>. Date accessed: 13 Feb. 2015.

Clark, W., K. Logan, R. Luckin, A. Mee, and M. Oliver. 2009. "Beyond Web 2.0: mapping the technology landscapes of young learners." Journal of Computer Assisted Learning 25 (1): 5669.

Colley, H., P. Hodkinson, and J. Malcolm. 2003. Informality and Formality in Learning: a report for the Learning and Skills Research Centre. London: LSRC. 
Cox, M. 2013. "Formal to informal learning with IT: research challenges and issues for e-learning." Journal of Computer Assisted Learning 29 (1): 85-105.

Crook, C. 2012. "The 'digital native' in context: tensions associated with importing Web 2.0 practices into the school setting." Oxford Review of Education 38 (1): 63-80.

Dabbagh, N., and A. Kitsantas. 2012. "Personal Learning Environments, social media, and selfregulated learning: A natural formula for connecting formal and informal learning." Internet and Higher Education 15(1): 3-8.

Dede, C. 2008. A seismic shift in epistemology. EDUCAUSE Review 43 (3): 80-81. Retrieved March 4, 2009, from http://net.educause.edu/ir/library/pdf/ERM0837.pdf

DiVall, M. V. and J. L. Kirwin. 2012. "Using Facebook to facilitate course-related discussion between students and faculty members." American Journal of Pharmaceutical Education 76 (2): 1-5

Ebner, E., C. Lienhardt, M. Rohs, and I. Meyer. 2010. "Microblogs in Higher Education - A chance to facilitate informal and process-oriented learning?" Computers \& Education 55 (1): 92-100.

Eshach, H. 2007. "Bridging In-school and Out-of-school Learning: Formal, Non-Formal, and Informal Education.” Journal of Science Education and Technology 16 (2): 171-190.

European Commission (EC). 2001. Communication: making a European area of lifelong learning a reality. Retrieved January 13, 2014, from: http://eurlex.europa.eu/LexUriServ/LexUriServ.do?uri=COM:2001:0678:FIN:EN:PDF

Eynon, R. 2009. "Mapping the digital divide in Britain: implications for learning and education." Learning, Media and Technology 34 (4): 277-290. doi: 10.1080/17439880903345874

Eynon, R. and L. Malmberg. 2011. "A typology of young people's Internet use: implications for education." Computers and Education 56 (3): 585-595.

Ferguson, R., D. Faulkner, D. Whitelock and K. Sheehy. 2014. "Pre-teens' informal learning with ICT and Web 2.0". Technology, Pedagogy and Education. DOI: 10.1080/1475939X.2013.870596

Gao, F., T. Luo, and K. Zhang. 2012. "Tweeting for learning: A critical analysis of research on microblogging in education published in 2008-2011." British Journal of Educational Technology 43(5): 783-801.

Green, H., and C. Hannon. 2007. Their Space: Education for a digital generation. London: Demos.

Greenhow, C. 2010. "The role of youth as cultural producers in a niche social network site." New Directions in Youth Development: Theory, Research \& Practice, 128: 55-64.

Greenhow, C. 2011. "Online social networks and learning." On the Horizon, 15(1): 4-12.

Greenhow, C., L. Burton and B. Robelia. 2011. "Help from my "Friends:" Social capital in the social network sites of low-income high school students." Journal of Educational Computing Research, 45 (2): 223-245. 
Greenhow, C. and B. Gleason. 2014. "Social scholarship: Reconsidering scholarly practices in the age of social media." British Journal of Educational Technology, 45 (3): 392-402.

Greenhow, C., M. Menzer, and T. Gibhbins. 2015. "Re-thinking Scientific Literacy: Arguing Science Issues in a Niche Facebook Application." Computers \& Human Behaviour. doi:10.1016/j.chb.2015.06.031.

Greenhow, C. and E. Robelia. 2009a. "Old communication, new literacies: Social network sites as social learning resources.” Journal of Computer-mediated Communication, 14: 1130-1161.

Greenhow, C. and E. Robelia. 2009b. "Informal learning and identity formation in online social networks." Learning, Media and Technology, 34(2): 119-140.

Greenhow, C., E. Robelia, and J. Hughes. 2009. "Web 2.0 and classroom research: What path should we take now?" Educational Researcher, 38(4): 246-259.

Gruzd, A., K. Staves, and A. Wilk. 2012. "Connected scholars: Examining the role of social media in research practices of faculty using the UTAUT model." Computers in Human Behavior 28: $2340-2350$.

International Society for Technology in Education (ISTE). 2007. ISTE Standards for Students: Advancing digital age learning. Retrieved May 7, 2015, from: http://www.iste.org/standards/iste-standards/standards-for-students

Ito, M., S. Baumer, M. Bittanti, d. boyd, R. Cody, B. Herr-Stephenson, and H. Horst et al. 2010. Hanging Out, Messing around, and Geeking Out: Kids, Living and Learning with New Media. Cambridge, MA: MIT Press.

Ito, M., K. Gutierrez, S. Livingstone, B. Penuel, J. Rhodes, K. Salen, J. Schor, J. Sefton-Green, and S. Watkins. 2013. Connected Learning: An Agenda for Research and Design. Irvine, CA: Digital Media and Learning Research Hub.

Ito, M., H. Horst, M. Bittanti, d. boyd, B. Herr-Stephenson, P.G. Lange, et al. 2008. Living and learning with new media: Summary of findings from the Digital Youth Project. The John D. and Catherine T. MacArthur Foundation Reports on Digital Media and Learning. Retrieved January 30, 2009, from http://digitalyouth.ischool.berkeley.edu/report

Jenkins, H. with R. Purushotma, M. Weigel, K. Clinton, and A.J. Robison. 2009. Confronting the challenges of participatory culture: Media education for the 21st century. Cambridge, MA: MIT Press.

Junco, R., and S. R. Cotton. 2013. "No A 4 U: The relationship between multitasking and academic performance." Computers \& Education 59: 505-514.

Kirschner, A. P., and A. C. Karpinski. 2010. Facebook and Academic Performance. Computers in Human Behavior 26: 1237-1245.

Kop, R. and A. Hill. 2008. "Connectivism: Learning theory of the future or vestige of the past?" The International Review of Research on Open and Distributed Learning, 9 (3): n.p. Retrieved online at: http://www.irrodl.org/index.php/irrodl/article/viewArticle/523/1103\%2522 
Lai, K.W., F. Khaddage and G. Knezek. 2013. "Blending student technology experiences informal and informal learning." Journal of Computer Assisted Learning 29: 414-425

Lewin, C. and McNicol, S. 2014. Creating the Future Classroom: Evidence from the iTEC project. Full report. Manchester, UK: Manchester Metropolitan University. FP7 Grant Agreement No: 257566. http://itec.eun.org/web/guest/deliverables

Livingstone, D.W. 2001. Adults' informal learning: definitions, findings, gaps and future research: NALL Working Paper No 21. Toronto: University of Toronto. https://tspace.library.utoronto.ca/bitstream/1807/2735/2/21adultsinformallearning.pdf

Luckin, R., W. Clark, R. Graber, K. Logan, A. Mee, and M. Oliver. 2009. "Do Web 2.0 tools really open the door to learning? Practices, perceptions and profiles of 11-16 -year-old students." Learning, Media and Technology 34 (2): 87-104. doi: 10.1080/17439880902921949

Madden, M., S. Cortesi, U. Gasser, A. Lenhart, and M. Duggan. 2012. Parents, Teens, and Online Privacy. Pew Internet and American Life Project. http://www.pewinternet.org/Reports/2012/Teens-and-Privacy.aspx

Manca, S., and M. Ranieri. 2013. "Is it a tool suitable for learning? A critical review of the literature on Facebook as a technology-enhanced learning environment." Journal of Computer-assisted Learning 29(6): 487-504. doi: 10.1080/17439880902923606

Mao, J. (2014). "Social media for learning: A mixed methods study of high school students' technology affordances and perspectives." Computers in Human Behavior, 33: 213-223.

Mardis, M. A. 2013. "What it has or what it does not have? Signposts from US data for rural children's digital access to informal learning." Learning, Media and Technology 38 (4): $387-$ 406. doi: 10.1080/17439884.2013.783595

Mason, R. and F. Rennie. 2007. "Using Web 2.0 for learning in the community." The Internet and Higher Education 10 (3): 196-203.

Mathews, J. 2009, January 5. The Latest Doomed Pedagogical Fad: 21st-Century Skills. Washington Post. Retrieved May 7, 2015, from: http://www.washingtonpost.com/wpdyn/content/article/2009/01/04/AR2009010401532.html

Mazman, S.G., and Y.K. Usluel. 2010. "Modeling Educational Uses of Facebook." Computers in Education 55(2): 444-453.

Merchant, G. 2012. "Mobile practices in everyday life: Popular digital technologies and schooling revisited." British Journal of Educational Technology 43 (5): 770-782. doi:10.1111/j.14678535.2012.01352.x

Mills, N. 2011. "Situated Learning Through Social Networking Communities: The Development of Joint Enterprise, Mutual Engagement, and a Shared Repertoire." CALICO Journal 28 (2): 345-368. 
Ofcom. 2014. Adults' Media Use and Attitudes Report. London: Ofcom. Retrieved May 7, 2015, from: http://stakeholders.ofcom.org.uk/binaries/research/media-literacy/adults2014/2014_Adults_report.pdf

Partnership for 21 st century skills (P21). 2009. Framework for 21st century learning. Retrieved May 7, 2015, from: http://www.p21.org/storage/documents/1._p21_framework_2-pager.pdf Pimmer, C., S. Linxen, and U. Gröhbiel. 2012. "Facebook as a learning tool? A case study on the appropriation of social network sites from mobile phones in developing countries." British Journal of Educational Technology 43 (5): 726-738.

Prescott, J., S. Wilson, and G. Becket. 2013. "Facebook use in the learning environment: do students want this?" Learning, Media and Technology 38 (3): 345-350. doi:10.1080/17439884.2013.788027

Putnam, R. D. 1995. Bowling Alone: The Collapse and Revival of the American Community. New York, NY: Simon \& Schuster.

Ranieri, M. and I. Bruni. 2013. "Mobile storytelling and informal education in a suburban area: a qualitative study on the potential of digital narratives for young second-generation immigrants." Learning, Media and Technology 38 (2) 217-235. doi: $10.1080 / 17439884.2013 .724073$

Ranieri, M., S. Manca and A. Fini. 2012. "Why (and how) do teachers engage in social networks? An exploratory study of professional use of Facebook and its implications for lifelong learning." British Journal of Educational Technology 43 (5): 754-769.

Reynolds, R., and M. M. Chiu. 2013. "Formal and informal context factors as contributors to student engagement in a guided discovery-based program of game design learning." Learning, Media and Technology 38 (4): 429-462. doi: 10.1080/17439884.2013.779585

Robelia, B., C. Greenhow, and L. Burton. 2011. "Adopting environmentally responsible behaviors: How learning within a social networking application motivated students to act for the environment." Environmental Education Research, 17 (4): 553-575.

Sadler, T., S. Barab, and B. Scott. 2006. "What do Students Gain by Engaging in Socioscientific Inquiry." Research in Science Education 37: 371-391.

Schuck, S. and P. Aubusson. 2010. "Educational scenarios for digital futures." Learning, Media and Technology 35 (3): 293-305. doi: 10.1080/17439884.2010.509351

Sefton-Green, J. 2013. Learning at not-school: A review of study, theory, and advocacy for education in non-formal settings. Cambridge, MA: MIT Press.

Sefton-Green, J. 2004. Report 7: Literature review in informal learning with technology outside school. Bristol, England: Futurelab. ISBN: 0-9544695-7-7. Retrieved January 3, 2014, from: http://www2.futurelab.org.uk/resources/documents/lit_reviews/Informal_Learning_Review.p $\underline{\mathrm{df}}$ 
Selwyn, N. 2007. "Web 2.0 applications as alternative environments for informal learning - a critical review." Paper presented at OECD-KERIS Expert Meeting, Chegu, South Korea, Oct. 16-17. https://www1.oecd.org/edu/ceri/39458556.pdf

Selwyn, N. 2009. Faceworking: Exploring students' education-related use of Facebook. Learning Media and Technology, 34 (2): 157-174.

Selwyn, N. 2010. "Looking beyond learning: notes towards the critical study of educational technology." Journal of Computer Assisted Learning, 26: 65-73.

Selwyn, N. 2011. Social media in higher education. In Gladman, A., (Ed.), The Europa world of learning (pp. 1-9). London, UK: Routledge.

Siemens, G. 2005. "Connectivism: A learning theory for the digital age." International Journal of Instructional Technology and Distance Learning 2 (10): 3-10.

Silva, E. 2009, May. “Measuring Skills for 21st-Century Learning”. Phi Delta Kappan, 90 (9): 630634.

Social media [Def.1]. n.d. Oxford Dictionaries Online. In Oxford Dictionary. Retrieved March 17, 2015 from http://www.oxforddictionaries.com/us/definition/american_english/social-media

Tan, E. 2013. "Informal learning on YouTube: exploring digital literacy in independent online learning." Learning, Media and Technology 38 (4): 463-477. doi:10.1080/17439884.2013.783594

Trinder, K., J. Guiller, A. Margaryam, A. Littlejohn, and D. Nicol. 2008. Learning from digital natives: bridging formal and informal learning. York, UK: Higher Education Academy. http://www.gcu.ac.uk/media/gcalwebv2/academy/content/ldn/LDNFinalReport.pdf

Voogt, J. and N. Pareja Roblin. 2012. “A comparative analysis of international frameworks for 21st century competences: Implications for national curriculum policies". Journal of Curriculum Studies, 44 (3): 299-321.

Vygotsky, L. S. 1978. Mind in society: The development of higher psychological processes. Cambridge, MA: Harvard University Press.

Warschauer, M. and T. Matuchiank. 2010. "New Technology and digital worlds: Analyzing evidence in equity, use and outcomes." Review of Research in Education 34 (1): 179-225

Weigel, M., C. James and H. Gardner. 2009. "Learning: Peering Backward and Looking Forward in the Digital Era." International Journal of Learning and Media 1 (1): 1-18 http://www.mitpressjournals.org/doi/full/10.1162/ijlm.2009.0005

Windschitl, M. 2002. Framing constructivism in practice as the negotiation of dilemmas: An analysis of the conceptual, pedagogical, cultural, and political challenges facing teachers. Review of Educational Research, 72 (2), 131-175.

Yang Y., C. Crook and C. O'Malley. 2013. "Can a social networking site support afterschool group learning of Mandarin?" Learning, Media and Technology 39 (3): 267-282 doi: $10.1080 / 17439884.2013 .839564$ 